\title{
A Case of Foreign Accent Syndrome Resulting in Regional Dialect
}

\author{
Raveeni Naidoo, Erin M. Warriner, Wieslaw J. Oczkowski, Alexandre Sévigny, \\ Karin R. Humphreys
}

\begin{abstract}
Background: Foreign Accent Syndrome (FAS) is a rare acquired syndrome following neurological damage that results in articulatory distortions that are commonly perceived as a "foreign" accent. The nature of the underlying deficit of FAS remains controversial. We present the first reported Canadian case study of FAS following a stroke. We describe a stroke patient, RD, who suffered an acute infarction to the left internal capsule, basal ganglia and frontal corona radiata. She was diagnosed as having FAS without any persistent aphasic symptoms. Family, friends, and health care professionals similarly described her speech as sounding like she had a Canadian East Coast accent, a reported change from her native Southern Ontario accent. Method: An investigation of this case was pursued, incorporating neuroimaging, neuropsychological and speech pathology assessments, and formalized linguistic analyses. Results: Linguistic analyses confirmed that RD's speech does in fact have salient aspects of Atlantic Canadian English in terms of both prosodic and segmental characteristics. However, her speech is not entirely consistent with an Atlantic Canadian English accent. Interpretation: The fact that RD's speech is perceived as a regional variant of her native language, rather than the "generic foreign accent" of FAS described elsewhere, suggests that the perceived "foreignness" in FAS is not primarily due to dysfluencies which indicate a non-native speaker, but rather due to very subtle motor-planning deficits which give rise to systemic changes in specific phonological segments. This has implications for the role of the basal ganglia in speech production.
\end{abstract}

RÉSUMÉ: Un cas du syndrome de l'accent étranger se manifestant sous forme de dialecte régional. Contexte : Le syndrome de l'accent étranger (SAÉ) est un syndrome rare, acquis suite à une lésion neurologique qui provoque des distorsions de l'articulation communément perçues comme un accent «étranger ». La nature du déficit sous-jacent demeure controversée. Nous présentons le premier cas rapporté de SAÉ suite à un accident vasculaire cérébral. Le patient, RD, a subi un infarctus aigu de la capsule interne gauche, des noyaux gris centraux et de la couronne rayonnante frontale. Un diagnostic de SAÉ sans symptômes aphasiques persistants a été posé. Sa famille, ses amis et les professionnels de la santé décrivaient tous son accent comme un accent de la Côte est du Canada, ce qui représentait un changement par rapport à son accent d'origine du sud de l'Ontario. Méthode : L'étude de ce cas comprend la neuroimagerie, des évaluations neuropsychologiques et orthophoniques et des analyses linguistiques. Résultats : Les analyses linguistiques ont confirmé que le langage de RD présentait des caractéristiques marquées de l'anglais parlé dans les Provinces Atlantiques, tant en ce qui concerne les caractéristiques prosodiques que segmentales. Cependant, son langage n'est pas tout à fait semblable à l'accent anglais des Provinces Atlantiques. Interprétation : Le fait que l'accent de RD est perçu comme une variante régionale de sa langue maternelle plutôt que « l'accent étranger générique » du SAÉ décrit ailleurs suggère que l'aspect « étranger » perçu dans le SAÉ n'est pas dû principalement à des « dysfluences » qui indiquent que la personne qui parle est étrangère, mais bien à des déficits subtils de planification motrice qui donnent lieu à des changements systémiques de segments phonologiques spécifiques, ce qui met en cause le rôle des noyaux gris centraux dans la production du langage.

Can. J. Neurol. Sci. 2008; 35: 360-365

This paper presents a case study of a left-handed stroke patient (RD) with Foreign Accent Syndrome (FAS) without any persistent aphasic symptoms, resulting acutely from a left subcortical infarction involving the internal capsule, basal ganglia, and frontal corona radiata. Foreign Accent Syndrome is a rare and controversial acquired syndrome following neurological damage, which results in articulatory distortions that are commonly perceived as a "foreign" accent (see ${ }^{1}$ for a review), despite no previous personal or family history with that
From Joseph Brant Memorial Hospital (RN), Burlington; Integrated Stroke Unit (EMW), Hamilton Health Sciences; Department of Medicine, Division of Neurology (WJO), Departments of Communication Studies \& Multimedia - French (AS), Department of Psychology, Neuroscience \& Behavior (KRH), McMaster University, Hamilton, Ontario, Canada.

Received October 16, 2007. Final Revisions Submitted February 9, 2008. Reprint requests to: Karin R. Humphreys, Department of Psychology, Neuroscience \& Behaviour, McMaster University, 1280 Main St West, Hamilton, Ontario, L8S 4K1, Canada. 
accent. While many patients with FAS initially present as transiently mute or similar to a Broca-type of aphasia, the onset of the perceived accent typically becomes apparent when speech returns. ${ }^{2}$ Foreign Accent Syndrome most commonly occurs poststroke, and has been associated with a range of lesion sites. Stroke related damage resulting in FAS usually occurs in left hemispheric areas related with speech production, including Broca's area, pre-motor and motor areas, and the basal ganglia. ${ }^{1}$

This is the first reported case of FAS following a stroke in Canada and one of fewer than 20 cases reported globally with accompanying details of lesion location. The patient's accent was perceived by her family to have changed from her native Southern Ontario accent to a "Newfoundland" accent. Health professionals meeting her post-stroke thought that she was from Atlantic Canada. The diagnosis of FAS was in fact delayed, as it was initially assumed that her acquired "accent" was her native one, and not a symptom of disordered speech. This case is notable in that while her speech is perceived as having undergone an accent or more specifically a regional dialect change, she does not sound like a non-native English speaker. In contrast, almost all other reported cases in the literature presented with an accent that was decidedly "foreign" to their native language. This feature of the case helps us to answer the perplexing question of what the underlying deficit is in FAS, including the question of why it sounds "foreign," rather than like the disordered speech characteristic of other speech/motor disorders, associated with brain injury, including aphasia, dysarthria, or apraxia of speech (AOS). This paper examines these questions in light of RD's case on the basis of clinical and neuroanatomical findings, as well as formalized linguistic analyses of her speech. Comparing this case to other reported cases of FAS, we then make some observations as to possible neural mechanisms underlying both FAS and normal speech production.

\section{Case History}

\section{Ethics}

This study has satisfied the ethical requirements of the Research Ethics Board of Hamilton Health Sciences/McMaster University Faculty of Health Sciences. Written informed consent was obtained from the patient to perform these investigations and to disseminate the findings.

\section{Patient}

A 50-year-old monolingual English speaking Canadian woman (RD), has lived in Southern Ontario her entire life (Windsor then Hamilton), as had her parents, with her only travel being to Florida on vacation. She has had only minimal contact with anyone speaking a dialect other than her native one. She has a high school education, and worked in the food service industry. She had been a heavy smoker. A handedness inventory conducted two months post-stroke showed her to be strongly left-handed, and both she and her husband confirmed that this was the case pre-morbidly as well.

\section{Clinical Findings}

Her symptoms began at work, where she felt faint and confused. Her symptoms persisted after going home and taking a nap, and by this time she had developed right-sided weakness.
She then presented to the hospital, where a neurological examination identified a dense right hemiplegia, central facial nerve palsy, and slightly dysarthric speech. In general conversation, her receptive and expressive language seemed reasonably well preserved, aside from some mild word-finding difficulties. Following a CT scan (see following section on neuroanatomical findings), she was diagnosed as having suffered a left hemisphere ischemic stroke, and was admitted to the Integrated Stroke Unit at the Hamilton General Hospital.

A bed-side speech and language assessment conducted at five days post-stroke revealed mild flattening of the right naso-labial fold secondary to a central facial palsy and a mild to moderate oral-pharyngeal dysphagia. Her speech was described to be slow in rate, consisting of imprecise consonants, mono-pitch, and mono-loudness. A language screen indicated generative naming and word finding difficulties. At a follow-up bedside assessment 14 days post-stroke there was resolution of the oral-pharyngeal dysphagia, but no change in her speech pattern. After two months post-stroke, she continued to present with decreased tone on the right upper and lower lips on spreading and puckering. Her tongue deviated mildly to the right on protrusion and had mildly decreased range of motion to the right on lateralization. A videofluoroscopic swallowing study showed some limited descent of the epiglottis but no aspiration was noted on all food and liquid trials.

At 1.5 months post-stroke, no striking cognitive impairments were noted on a clinical neuropsychological assessment. Mild to moderate inefficiencies were, however, noted in the following areas: mild expressive deficits from word finding problems in conversations and on formal measures of expressive vocabulary, confrontation naming, as well as both semantic and phonemic verbal fluency; right-sided inattention in visual scanning/ searching; moderate inefficiencies in her processing speed; mild reductions in mental control and working memory; verbal retrieval deficits; and mild executive dysfunction. Her test pattern was consistent with the neuroradiological scans (see below), suggesting bilateral interference in anterior-subcortical circuitry, though more predominantly involving left than right hemisphere processes.

\section{Neuroanatomical Findings}

Initial CT scan of the brain on admission revealed multifocal areas of patchy hypoattenuation seen in the subcortical white matter within the left and right frontal lobes consistent with chronic microangiopathic ischemia. A CT scan of the brain two days later revealed a well-defined area of hypoattenuation involving the left internal capsule, left basal ganglia, and left frontal corona radiata in keeping with infarction. An MRI performed approximately one month after symptom onset demonstrated an area of involvement in the anterior and posterior limb of the internal capsule as well as the superior portion of the lenticular nucleus consistent with an evolving infarct. The MRI also identified multifocal areas of high signal abnormality within the subcortical white matter bilaterally involving the corona radiata and centrum semiovale (see Figure).

\section{Language and Speech Findings}

Post-stroke RD was perceived by family to have a "different accent," which they described as speaking like a "Newfoundlander." Notably, it was not immediately obvious to those 
meeting her for the first time that her apparent accent represented a change from her pre-morbid state - while health professionals clearly noticed that she had some speech deficits, they nonetheless initially assumed that she was from Atlantic Canada. She herself did not identify any change in her accent. Information obtained from her family helped to clarify that the perceived new accent was not her native one.

At five days post-stroke, RD's speech was at a slow rate, with generally flattened prosody and had a breathy voice quality. A language screen indicated generative naming and word finding difficulties. However, the Assessment of Intelligibility of Dysarthric Speech Test $^{3}$ administered one month post-stroke onset indicated $100 \%$ speech intelligibility. Portions of the Boston Diagnostic Aphasia Examination, Third Edition $\left(\mathrm{BDAE}^{4}\right)$ were also administered one month post-stroke onset. Her recitation skills were impaired (scored 1/7) and she failed on the melody task (scored 0). Word finding difficulties were noted on the short form of the Boston Naming Test. She verbally named only 6/15 pictures accurately but had no difficulty matching the written word to the target picture. Circumlocutions, hesitations, searching behaviours for the word, and semantic paraphasias were noted. By three months post-stroke, these word finding problems had improved greatly.

Linguistic analyses of her speech were conducted based on three interviews with researchers at approximately one-week intervals, beginning at four weeks post-stroke, as well as on her

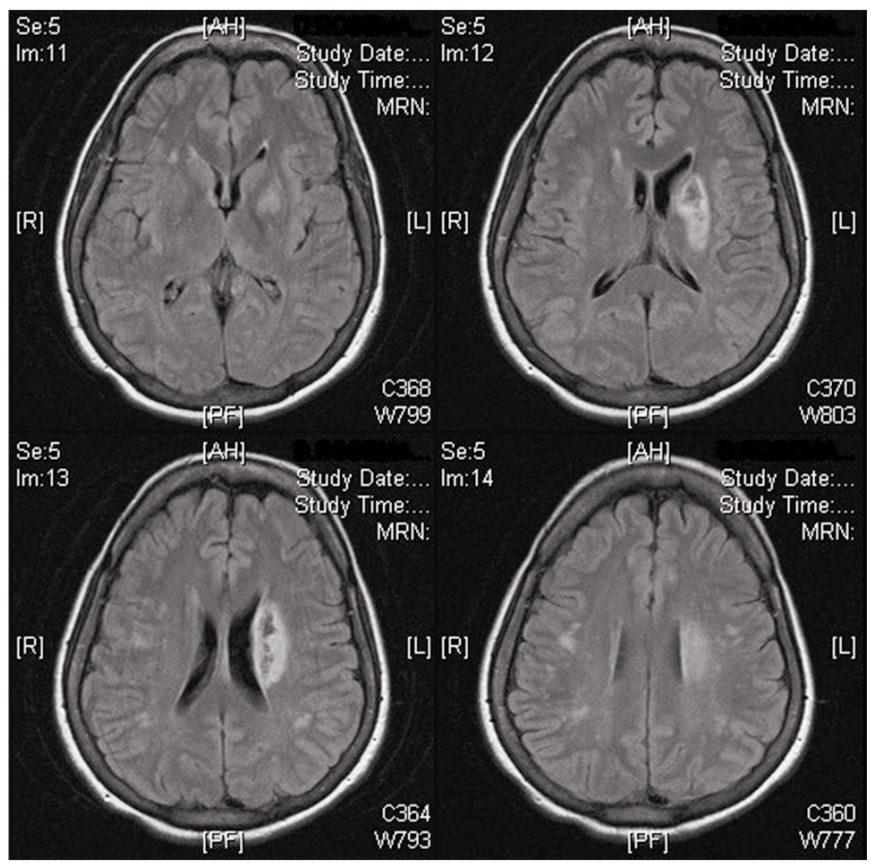

Figure: MRI display with FLAIR sequences showing a lacunar infarction on the left side. The infarction is in the left internal capsule involving the anterior and posterior limb as well as the superior portion of the lenticular nucleus. The antero-posterior dimension of the infarction is approximately $3 \mathrm{~cm}$. sessions with a Speech-Language Pathologist. The interviews were recorded, and later transcribed and analyzed. A variety of recording means were used, including one video recording, and also high quality digital audio recordings onto either recordable compact disc (CDR) or a flash memory recorder. We variously used a Shure head-worn unidirectional microphone, and a Shure boundary microphone. In order to elicit speech during these interviews, RD engaged in spontaneous conversation with both the researchers and her husband, and she was asked to read passages and to describe simple pictures in a sentence. Phonological analyses were conducted by two of the authors, in consultation with a third, all of whom are linguistically trained. These were done by ear, by repeated listening to the recordings, until consensus was reached. These observations were then confirmed by two other independent, linguistically trained listeners.

Phonologically, RD's speech was characterized by changes both in some specific phonological segments and in prosody. The segmental changes that lead to the perception of an Atlantic Canadian accent included both consonant and vowel changes. For consonants, we observed the stopping of "th" (e.g. "dat" for "that" and "tink" for "think"), and the replacement of "ng" sounds at the ends of words with an "n" (e.g. "hurting" was pronounced as "hurtin"). Both of these were reported by RD's family to be novel to her postmorbid speech. Vowel changes included the raising of back vowels, and the opening of some vowels, and diphthongization (e.g. "greasy" was pronounced "gracey", and "dog" was pronounced to rhyme with "rogue"). A number of prosodic changes likely also contributed to the perception of an Atlantic dialect, including overall slowing of her speech, and prolongation of vowels, often resulting in diphthongization. There was also frequently a drawling-like pitch slide on word contours. See Wells ${ }^{5}$ for an overview of the characteristics of Atlantic Canadian English. Notably, these were not global changes throughout her speech, but occurred intermittently. For example, the majority of "th" segments were pronounced as " $d$ " but there were several clear instances of intact "th" sounds. The prosodic changes mentioned above were even more variably realized in her speech.

However, RD's speech was not completely consistent with an East coast dialect, either in segmental or prosodic aspects. These inconsistent features included the epenthetic insertion of vowels into consonant clusters, such as the addition of a schwa to some consonant clusters (e.g. "dream" pronounced as "duh-ream"). There was also a general slowing of transitions between segments, the occasional palatalization of $/ \mathrm{s} /$ and $/ \mathrm{z} /$, and a slight lack of control over the release of fricative consonants, exacerbated when they occurred in consonant clusters.

There was an overall flattening of her prosody, including the reduction of both pitch and loudness contours that signal both linguistic and emotional contrasts. She also had difficulty copying the intonation patterns of her Speech-Language Pathologist and her family. Her speech was generally slowed, and she had difficulty increasing the rate when prompted with rhythmic cues. Her singing was also altered and she displayed a dramatic attenuation of pitch contour, although the directionality of her pitch changes and rhythm on known songs (e.g. Happy Birthday) remained reasonably accurate. All of these changes to her speech were less prominent when she read as opposed to her spontaneous speech, with the exception of her sentence level 
prosody, which was even flatter while reading. However, this seems likely due to the fact that a flatness of reading prosody is not uncommon amongst less skilled oral readers. ${ }^{6}$ Notably, at one stage during a recording session, the conversation became highly animated, and her prosody during this time appeared nearnormal.

Her examinations revealed kinematic changes, including reduced range of motion with the tongue and lips and limited descent of the epiglottis. These observations, in combination with the acoustic properties of her speech including the reduced pitch range and elongation of vowels gave rise to the clinical judgment that her speech was consistent with a tense vocal tract posture, (i.e. increased laryngeal tension).

Generally, her speech was highly intelligible, and, to an untrained observer, not necessarily obviously pathological. Furthermore, no listeners to our knowledge mistook her for being a non-native speaker of English.

\section{Interpretation}

We report a case of Foreign Accent Syndrome without persisting aphasic symptoms, in a 50-year-old woman from Southern Ontario who suffered an acute infarction to the left internal capsule, lenticular nucleus of the basal ganglia and frontal corona radiata. Despite resolution of her mild expressive deficit (anomia), RD's speech had lasting phonological changes post-stroke that were perceived as not a foreign accent but rather a regional dialect variant, in this case a "Newfoundland accent." Linguistic analyses showed her speech to have many features, both in terms of phonological segments and in prosody, that were indeed consistent with Atlantic Canadian English, but there were also many features of her speech that were not consistent with this, nor were they characteristic of any other particular dialect.

The most central question FAS raises is whether the changes that occur should be described as a true accent change, and if not, why FAS speech is nonetheless perceived as "foreign." Underlying these issues is the more fundamental question of how FAS relates to other motor speech disorders, specifically the dysarthrias and apraxia of speech, both in terms of clinical and neurological findings. The case presented here has several elements that can shed light on these questions. First, linguistic analyses determined that RD's speech was not entirely consistent with an accent change, despite observers' impressions. While this does not disprove that there are other cases of FAS which constitute true accent changes, it adds to the growing collection of observations of FAS that do not (see review ${ }^{1}$ ). Instead, RD's speech is consistent with a mild deficit in motor planning. The segmental distortions tend to occur on the most motorically difficult segments or sequences, which require the most precise timing (e.g. "th" is produced as " $t$ " or "d", the general slight lack of control over the release of fricatives, and consonant clusters show occasional vowel insertion). This explanation does not fully explain the prosodic changes in her speech, which could be in part due to a possible change in RD's vocal tract tension. While this gives some support to theories that characterize FAS as being due to changes in vocal tract tension, as in, 7,8 the segmental changes remain more consistent with a motor planning deficit.

The next question concerns why FAS speech tends to be perceived as foreign. There are several cases in the literature where it is reported that some observers thought the post-morbid speech reflected one accent, but other observers took it to be another (e.g. Swedish, German, or "Asian"). ${ }^{7}$ There has been some suggestion that FAS does not result in a patient acquiring any specific regional accent, but rather some "generic foreign accent" that is varyingly perceived by listeners. ${ }^{7,9}$ However, in this case, the patient was never perceived to sound like a nonnative speaker of English, but was instead widely perceived as having a fairly specific regional dialect of English, features of which were confirmed by linguistic analysis. Note, most people who interacted with RD live in Canada and, thus, had some familiarity with the Atlantic Canadian English accent, so this was a readily available characterization for these listeners. If RD had presented elsewhere in the world, we suggest that it is most likely that listeners would have perceived it as another accent, although still differing from a southern Ontarian accent (an Irish English accent is also somewhat consistent with RD's speech). Nevertheless, the characteristics of her speech are such that it is unlikely that any English speakers would perceive her as a nonnative English speaker. As this is a case of a perceived accent change without the perception of non-native speaker status, it directly contradicts the account offered by Avila and colleagues ${ }^{10}$ that the perception of a foreign accent is simply a result of listeners interpreting the accompanying dysfluencies and hesitations as being characteristic of a non-native speaker. Instead, we suggest that there are some systematic phonological changes that occur in FAS (although the exact nature of these changes may differ from patient to patient). Critically, these changes are in line with permissible human speech patterns, unlike those seen in dysarthria. Listeners hear the FAS patient's speech, and interpret those changes by picking out some salient features, and attributing them to a type of speech that they are familiar with, that is somewhat consistent with those phonological features.

We can then compare this case to other cases of FAS, and to other acquired neurogenic motor speech production disorders. Foreign Accent Syndrome is not associated with a particularly consistent pattern of lesions, although reviews have shown the damage to be typically left hemisphere, often with involvement of the precentral or inferior frontal gyri, or with involvement of the basal ganglia and insula. ${ }^{11,12}$ The suggestion is that what these cases have in common despite the lack of lesion overlap is that they all constitute a disruption of the motor speech network, which includes both cortical and subcortical components, and their connections. ${ }^{1,13}$ The lesions in this case show significant subcortical and white matter involvement, with little cortical damage. The left basal ganglia is the most notable point of overlap between this case and other reported cases of FAS, although there is also damage to several other interconnected left hemisphere areas involved in the motor control required for speech, including the posterior limb of the internal capsule and frontal corona radiata. ${ }^{14}$

Finally, we ask what the underlying deficit is of FAS, and what the relationship is between FAS and other speech-motor disorders following stroke, such as the dysarthrias (especially spastic or ataxic dysarthria), or apraxia of speech. Neither the clinical nor neurological findings of this case are particularly consistent with dysarthria. Her speech characteristics are, however, remarkably similar to AOS, which is defined as a deficit of motor planning/programming. Similarities include her overall slowed speech, and slowed transitions between segments, 
abnormal prosody, and fairly consistent segmental distortions that are perceived as sound substitutions. ${ }^{15}$ These distortions in RD's speech are consistent with either a speech motor control or motor programming/planning deficit, both of which are also consistent with the observed damage to the basal ganglia. Several researchers have suggested that FAS is really a mild case of AOS, ${ }^{16,17}$ although this is disputed. ${ }^{1,13}$ While there is no single lesion site clearly responsible for AOS, the insula has been frequently implicated, ${ }^{18}$ which in RD's case appears intact, although notably, adjacent structures are damaged. Prosodic distortions are commonly observed in both AOS and FAS, and RD's prosody plays a role in creating the perception of an Atlantic Canadian accent, in the way it changes her vowel quality. Although Blumstein and Kurowski conclude that FAS is primarily a prosodic disorder, ${ }^{1} \mathrm{RD}$ 's prosody is much flatter than the alterations they describe. Furthermore, even though prosodic distortions are common in AOS, it is not clear RD's flattened prosody can be accounted for by the same motor control mechanisms of the basal ganglia that we suggest contribute to the other changes in her speech. In right handed individuals, there is typically right hemispheric control of prosody. Because RD is left handed, there may be some unexpected variations in her hemispheric contributions to prosodic function. Alternatively, it is possible that at least some of RD's prosodic changes are attributable to changes in vocal tract tension, rather than a motor planning deficit.

This leads us to the several limitations to the conclusions we can draw from this study. Functional MRI or Wada assessments were not available to clearly identify the lateralization or distribution of various aspects of RD's language functions. Because RD is left-handed, a direct comparison to the lesion sites and symptomatology of other reported (predominantly right-handed) patients is not straightforward. On the other hand, adding this case to the literature broadens it in this respect. Additionally, as this patient showed evidence of having chronic, diffuse damage prior to the infarction, the neuroanatomical conclusions we can draw about the brain regions involved in FAS are somewhat less precise. Ideally, we would have been able to compare RD's speech to audio recordings of her pre-morbid speech. However, no such recordings appear to exist, so we compared her speech to regional norms, the speech of her family, and used the family's untrained reports of how her speech had changed.

One suggestion to stem from this case is that FAS may in fact be more prevalent than is commonly diagnosed. Furthermore, if FAS is a type of AOS, which is consistent with this case but not conclusive, we suggest that AOS may sometimes present itself as a regional dialect change, which may also lead to underdiagnosis. In this case, the FAS was originally not detected because it was assumed that RD's speech was simply characteristic of a regional variant of English (although it was not assumed that her speech was unaffected by the stroke; deficits were identified, but the changes relevant to FAS were not identifiable until knowledge was obtained about her pre-morbid state). Clinicians are likely to notice when a patient has speech motor deficits that result in speech that seems to have a foreign accent even when speaking what is known to be their first language. However, as in this case, if the speech characteristics are attributable to a regional dialect, the changes may remain undetected by clinicians. This underscores the importance of talking to family members about whether they notice any changes in the patient's speech. However, in cases like this, the accent change itself may not be judged to require clinical intervention, given the excellent intelligibility of speech. In this case, we note that the most significant aspect of the accent change for RD was the fact that she knew from being told that her accent had changed, despite not being able to hear the changes herself.

This case provides a very useful addition to our knowledge about FAS. It adds support to the basal ganglia as an important lesion site in FAS, and also points further to the role of the basal ganglia in fine aspects of speech motor planning. There is also some limited evidence for a possible role of vocal tract tension in some of the vocal changes observed in FAS. Most importantly, it clearly demonstrates how subtle phonological changes can give rise to the perception of a different (non-pathological sounding) accent. Furthermore, it is not necessarily a "generic foreign accent" that results. Instead, the specific phonological changes that occur may be unique to each individual, reflecting differences in damage within the motor speech network. These changes can give rise to specific-sounding accents, including ones that sound like a regional dialect change, rather than a complete foreign accent.

\section{ACKNOWLEDGEMENTS}

This work was supported in part by Natural Sciences and Engineering Research Council of Canada grant \#293145 to KRH. The authors thank Judy Thomas, Scott Watter, Lars Wessman, Georges Sévigny, Raageen Kanjee, Nina Jobanputra and Andrew Cooper for their comments and assistance. We also thank three anonymous reviewers for their helpful suggestions. And finally, we are especially grateful to RD for her participation.

\section{REFERENCES}

1. Blumstein SE, Kurowski $K$. The foreign accent syndrome: a perspective. J Neurolinguist. 2006;19(5):346-55.

2. Kurowksi KM, Blumstein SE, Alexander M. The foreign accent syndrome: a reconsideration. Brain Lang. 1996;54(1):1-25.

3. Yorkston KM, Beukelman DR. Assessment of intelligibility of dysarthric speech. Texas: Pro-Ed, Inc.; 1984.

4. Goodglass H, Kaplan E, Barresi B. The assessment of aphasia and related disorders. 3rd ed. Philadelphia: Lippincott, Williams \& Wilins; 2001

5. Wells JC. Accents of English. Cambridge: Cambridge University Press; 1982.

6. Schwanenflugel P, Hamilton A, Kuhn M, Wisenbaker J, Stahl S. Becoming a fluent reader: reading skill and prosodic features in the oral reading of young readers. J Educ Psychol. 2004; 96(1):119-29.

7. Ingram JCL, McCormack PF, Kennedy M. Phonetic analysis of a case of foreign accent syndrome. J Phonetics. 1992;20:457-74.

8. Moen I. A case of the 'foreign accent syndrome'. Clin Linguist Phonet, 1990;4(4):295-302.

9. Blumstein SE, Alexander MP, Ryalls JH, Katz W, Dworetzky B. On the nature of the foreign accent syndrome: a case study. Brain Lang. 1987;31(22):215-44.

10. Avila C, Gonzalez J, Parcet M, Belloch V. Selective alteration of native, but not second language articulation in a patient with foreign accent syndrome. Neuroreport. 2004;15(14):2267-70.

11. Scott SK, Clegg F, Rudge P, Burgess P. Foreign accent syndrome, speech rhythm and the functional neuroanatomy of speech production. J Neurolinguist. 2006;19(5):370-84. 
12. Carbary TJ, Patterson JP, Snyder PJ. Foreign accent syndrome following a catastrophic second injury: MRI correlates, linguistic and voice pattern analyses. Brain Cogn. 2000;43(13): $78-85$.

13. Fridriksson J, Ryalls J, Rorden C, Morgan PS, George MS, Baylis GC. Brain damage and cortical compensation in foreign accent syndrome. Neurocase. 2005;11(5):319-24.

14. Riecker A, Mathiak K, Wildgruber D, Erb M, Hertrich I, Grodd W, et al. fMRI reveals two distinct cerebral networks subserving speech motor control. Neurology. 2005;64(4):700-6.
15. McNeil MR, Robin DA, Schmidt RA. Apraxia of speech: definition, differentiation, and treatment. In: McNeil M, editor. Clinical management of sensorimotor speech disorders. New York: Thieme; 1997. p. 311-43.

16. Coelho CA, Robb M. Acoustic analyses of foreign accent syndrome: an examination of three explanatory models. J Med Speech-Lang Pa. 2001;9(4):227-42.

17. Moen I. Foreign accent syndrome: a review of contemporary explanations. Aphasiology. 2000;14(1):5-15.

18. Dronkers NF. A new brain region for coordinating speech articulation. Nature. 1996;384(6605):159-61. 